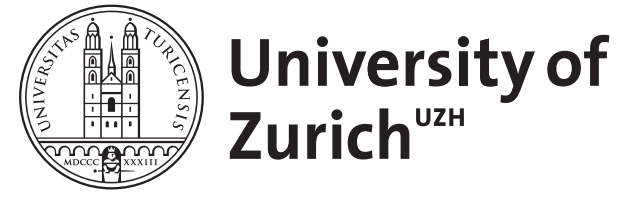

\title{
The idea of an axial age : A phenomenological reconsideration
}

Dalferth, Ingolf U

DOI: https://doi.org/10.1515/nzsth-2012-0001

Posted at the Zurich Open Repository and Archive, University of Zurich ZORA URL: https://doi.org/10.5167/uzh-69456

Journal Article

Published Version

Originally published at:

Dalferth, Ingolf U (2012). The idea of an axial age : A phenomenological reconsideration. Neue Zeitschrift für systematische Theologie und Religionsphilosophie NZSTh, (54):127-146.

DOI: https://doi.org/10.1515/nzsth-2012-0001 
IBZ Online

Internationale Bibliographie der geistes- und sozialwissenschaftlichen Zeitschriftenliteratur

Autor: Dalferth, Ingolf U.

Aufsatztitel: The Idea of an Axial Age. A Phenomenological Reconsideration

Zeitschrift: Neue Zeitschrift für Systematische Theologie und Religionsphilosophie

Band: 54

Nummer: 2

Seite(n): $127-147$

Erscheinungsjahr: 2012

Verlag: De Gruyter, Berlin, Boston

ISSN: $0028-3517$

Sprache (Artikel): Englisch

Sachgebiet (Artikel): Theologie, Religion; Philosophie

Schlagwörter: Religionsphilosophiephilosophy of religionphilosophie de la religionPhilosophiephilosophyReligionPhänomenologiephenomenology

Zugang bereitgestellt von: UZH Hauptbibliothek / Zentralbibliothek Zürich

Copyright $\odot$ 2011-2017 by Walter de Gruyter GmbH

Powered by PubFactory 